Irene J. Zaal

Carolina F. Spruyt

Linda M. Peelen

Maarten M. J. van Eijk

Rens Wientjes

Margriet M. E. Schneider

Jozef Kesecioglu

Arjen J. C. Slooter

\title{
Intensive care unit environment may affect the course of delirium
}

Received: 9 May 2012

Accepted: 19 September 2012

Published online: 24 October 2012

(C) Springer-Verlag Berlin Heidelberg and ESICM 2012
I. J. Zaal (®) - C. F. Spruyt ·

L. M. Peelen - M. M. J. van Eijk .

J. Kesecioglu - A. J. C. Slooter

Department of Intensive Care Medicine,

University Medical Centre Utrecht,

Heidelberglaan 100, 3584 CX Utrecht,

The Netherlands

e-mail: i.j.zaal-2@umcutrecht.nl

Tel.: +31-88-7561116

Fax: $+31-88-7561160$

L. M. Peelen

Julius Centre for Health Sciences \& Primary Care, University Medical Centre Utrecht,

Utrecht, The Netherlands

R. Wientjes

Department of Medical Technology and Clinical Physics, University Medical

Centre Utrecht, Utrecht, The Netherlands

M. M. E. Schneider

Department of Internal Medicine, University Medical Centre Utrecht, Utrecht, The Netherlands
Abstract Purpose: Delirium is a common disorder in intensive care unit (ICU) patients. It is unclear whether ICU environment affects delirium. We investigated the influence of ICU environment on the number of days with delirium during ICU admission. Methods: In this prospective before-after study, ICU delirium was compared between a conventional ICU with wards and a single-room ICU with, among others, improved daylight exposure. We included patients admitted for more than $24 \mathrm{~h}$ between March and June 2009 (ICU with wards) or between June and September 2010 (single-room ICU). Patients who remained unresponsive throughout ICU admission were excluded. The presence of delirium in the preceding $24 \mathrm{~h}$ was assessed daily with the confusion assessment method for the ICU (CAM-ICU) by research physicians combined with evaluation of medical and nursing charts. The number of days with delirium was investigated with Poisson regression analysis. Results: We included 55 patients (449 observation days) in the ICU with wards and 75 patients (468 observation days) in the single-room ICU. After adjusting for confounding, the number of days with delirium decreased by 0.4 days (95\% confidence interval $0.1-0.7)$ in the singleroom ICU $(p=0.005)$. The incidence of delirium during ICU stay was similar in the ICU with wards $(51 \%)$ and in the single-room ICU (45\%, $p=0.53)$. Conclusions: This study is the first to show that ICU environment may influence the course of delirium in ICU patients.

Keywords Delirium · Delirium management - Intensive care . Intensive care environment . Nursing care

\section{Abbreviations}

APACHE Acute physiology and chronic health evaluation

CAM-ICU Confusion assessment method in intensive care unit

CCI Charlson co-morbidity index

CI

DSI

GCS

ICU Confidence interval

IQR

LOS

OR

RASS Richmond agitation and sedation score

SD Standard deviation

SOFA Sequential organ failure assessment

UMCU University Medical Centre Utrecht 


\section{Introduction}

Delirium is a common condition in intensive care unit (ICU) patients [1, 2], characterized by a disturbance of consciousness and attention with a change in cognition and fluctuating course [3]. Delirium in the ICU is associated with complications and adverse outcomes including prolonged hospital stay $[4,5]$ and increased morbidity and mortality [6-8].

In non-ICU patients, non-pharmacological strategies could prevent delirium [9-11]. These include proactive geriatric consultation [9] and education of medical and nursing staff with special attention to known risk factors $[10,11]$. In ICU patients, non-pharmacological measures have hardly been studied in relation to delirium [12]. Still, the ICU environment with continuous light and noise, around the clock personnel and lack of orientation points is assumed to play a role in the development of delirium [12-15]. A previous study in ICU patients suggested that isolation and the absence of daylight were associated with an increased risk of delirium [13]. However, this study may have been biased as isolation and bed assignment may have been dependent on disease characteristics.

The ICU design can ameliorate healthcare outcomes, and lead to improved patients' sleep and a reduced frequency of hospital-acquired infections and medical errors by influencing circadian rhythm, the immune response, and patient and staff behaviour [16]. The ICU of our institution recently moved to a new location, providing a unique opportunity to study the effects of a changed ICU environment on the course of delirium.

The aim of this study was to investigate the influence of ICU environment on the number of days with delirium.

\section{Methods}

Design and study population

This prospective, before-after study was performed in the 32-bed mixed ICU of the University Medical Centre Utrecht (UMCU), the Netherlands. Both in the ICU with wards and in the single-room ICU, the ICU has been divided into three units with 11 beds. All three units are equal in staffing, admission criteria and facilities. A waiver of informed consent was obtained from the local medical ethics committee.

We included all patients admitted for more than $24 \mathrm{~h}$ of one out of the three ICU units between March and June 2009 (ICU with wards) or between June and September 2010 (single-room). We excluded patients who were unable to speak Dutch and English, and those who remained unresponsive [defined as a Richmond agitation and sedation scale [17] (RASS) less than -3 and/or a Glasgow coma scale score [18] (GCS) no greater than 8] throughout ICU admission.

\section{Intervention}

ICU delirium, medication use and light intensities were compared between the ICU with wards and the singleroom ICU. Until March 2010, patients were admitted to a mixed ICU, divided over three large wards with 11,11 and 10 beds, and only curtains to separate patients from each other, see Fig. 1a. In March 2010, the ICU of the UMCU moved to a new location, set up as a patient-centred environment. The new ICU was again divided over three wards with 11, 11 and 10 beds. All patients have separate rooms designed to reduce noise and make patients feel at home, using soft warm colours and with a view, providing orientation and sufficient daylight. Patients are not exposed to unnecessary and excessive noise owing to the use of remote control monitors both inside and outside the patient rooms, noise-absorbent materials, glass sliding doors separating patient rooms from the corridors and improved alarm systems that filter and selectively send alarms to the nurses' cell phones. More information about the new ICU (Fig. 1b) is published elsewhere [19].
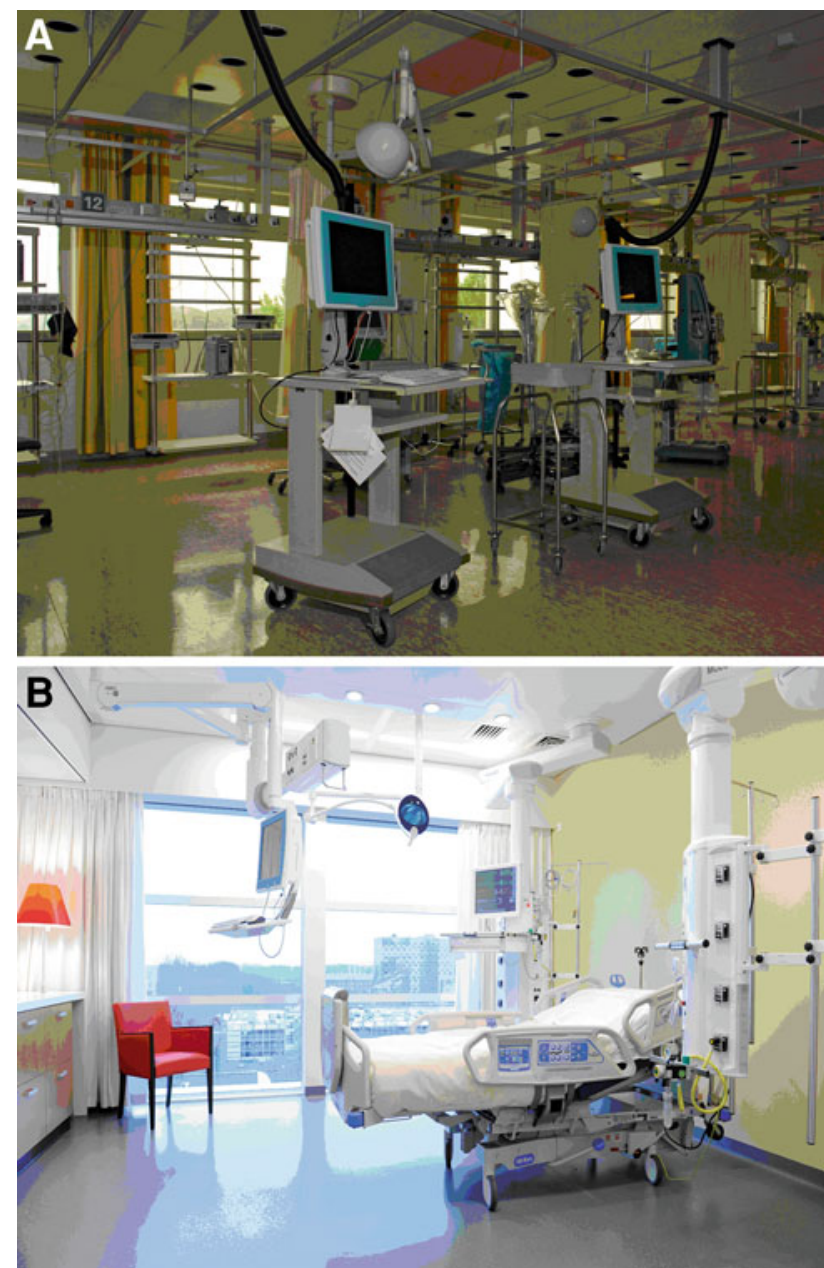

Fig. 1 Wards (old setting, a) and single-room (new setting, b) ICU 
The transition to the single-room ICU was a multicomponent intervention. Other factors did not differ between the two study periods. Importantly, the policy for family visits remained a 24-h open regimen and the doctorpatient and nurse-patient ratios were not altered. Teaching, practice and protocols for sedation, analgesia and delirium were not changed between study periods either.

\section{Data collection}

Data were collected prospectively, on a daily basis, 7 days a week. Standard demographic data were registered at inclusion. Co-morbidity at hospital admission was registered with the Charlson co-morbidity index [20]. Severity of illness at ICU admission was assessed using the acute physiology and chronic health evaluation (APACHE) version II score [21]. Severity of illness during ICU admission was estimated daily with the sequential organ failure (SOFA) score [22, 23]. We further recorded daily the use of physical restraints at any moment during the preceding day, defined from 10 A.M. to 10 A.M.

\section{Delirium assessment}

Delirium in the preceding day was assessed daily, 7 days a week, by two research physicians (IJZ and CFS) who received theoretical and bedside training by a neurologistintensivist (AJCS). This classification of mental status was as follows: (1) awake and not delirious during the preceding day, or (2) delirious at any moment during the preceding day, or (3) always unresponsive during the preceding day. The research physicians administered the Dutch version of the confusion assessment method for the ICU [24] (CAM-ICU) at a predefined time, between 10 and 12 A.M. If the patient was inaccessible, the evaluation was repeated between 3 and 5 P.M. Delirium often has a fluctuating course. To minimize the influence of this fluctuation the research physicians inspected the medical and nursing charts, including the results of the twice-daily CAM-ICU screening by trained bedside ICU nurses [25]. In case of doubt, a neurologist or psychiatrist was consulted who had the decisive vote with regard to the classification of mental status. The number of days with delirium was counted cumulatively during ICU admission, hence without taking different periods of delirium into account. The delirium severity index (DSI) was used to register daily the severity of delirium [26], based on the highest absolute RASS score in the preceding day. To determine interobserver variability in the mental status classification, the two research physicians and neurologist-intensivist assessed 36 patients simultaneously, where every observer was blinded to other observers' conclusions.

\section{Medication use}

Medication use was recorded with a computerized patient data monitoring system. For this study, we collected data on the use of medication that is mentioned in our protocols for sedation, analgesia and delirium, i.e. propofol, midazolam, oxazepam, temazepam, zopiclon, fentanyl, morphine, clonidine, haloperidol and quetiapine. During the study period, dexmedetomidine was not available in the Netherlands. In the statistical analyses, benzodiazepine dosages were converted in diazepam equivalents [27] and opioid dosages into fentanyl equivalents [28].

\section{Light intensity}

Light intensities were measured in September 2009 (ICU with wards) and in September 2010 (single-room ICU) with a light sensor (OSD15-E photodiode). The light sensor was attached $1 \mathrm{~m}$ from a randomly assigned patient's head to measure light intensity in 30-s intervals. After 3 days, the light sensor was moved to another, randomly assigned, patient. This cycle was repeated six times in both the old and the new setting. The Royal Netherlands Meteorological Institute (KNMI) headquarters is located in De Bilt, the Netherlands, just 2,700 m north of the UMCU. For the days of our light measurements we consulted the KNMI database and retrieved the daily observations of the weather station in De Bilt [29]. In this database the daily sunshine duration is calculated according to an algorithm developed and published by the KNMI [30]. The cloud cover is recorded in a graded scale from zero, indicating clear weather, to nine, completely overclouded.

\section{Outcomes and statistical analysis}

The primary outcome was the number of days with delirium during ICU admission. Secondary outcomes were the occurrence rate and severity of delirium.

The Student's $t$ test was used to study independent samples of continuous, normally distributed data and the Mann-Whitney $U$ test for continuous, skewed data. The Chi-square test was used to analyse categorical data. With Poisson regression analysis, we compared the cumulative number of days with delirium during ICU admission between the two settings, adjusted for the following confounding variables: age, gender, APACHE II, Charlson co-morbidity index, highest SOFA score during ICU admission, admission type (urgent vs. elective) and admitting discipline [in four categories: (1) medicine, (2) general surgery, (3) cardiology or cardiothoracic surgery, (4) neurology or neurosurgery]. We used logistic regression analysis to study the association between the two settings and the occurrence of delirium, adjusted for the 
possible confounders mentioned above. We used linear regression analysis to compare the severity of delirium, based on the cumulative DSI per patient divided by the total number of days with delirium for the particular patient, adjusting for the same covariates. We tested for multicollinearity in our multivariable regression analyses. Interobserver variability was expressed as $\kappa$ score.

We computed total light intensity over $24 \mathrm{~h}$ by summing the measurements of the 30 -s intervals. Dividing this total light intensity by the number of measurements provides a mean light intensity over $24 \mathrm{~h}$. Similarly, we calculated the mean light intensity during the day (07.00 A.M. -10.00 P.M.) and the night (10.00 P.M.07.00 A.M.).

All statistical analyses were performed using SPSS $17.0^{\circledR}$, SPSS inc., Chicago, Illinois, USA. A two-sided $p$ value less than 0.05 was considered statistically significant. Variance inflation factors (VIF) of at least 10 and tolerance values (1/VIF) less than 0.1 were considered as values indicating problems of multicollinearity.

\section{Results}

In the ICU with wards, 65 patients were eligible of whom 10 remained unresponsive. In the single-room ICU, a total of 91 patients were assessed. We excluded 16 patients: one because the patient did not speak/understand Dutch or English sufficiently to apply the CAM-ICU and 15 others because they remained unresponsive throughout ICU admission. Therefore, our study population included 55 patients in the ICU with wards (449 observation days) and
75 patients in the single-room ICU (468 observation days). Baseline characteristics of the study population are shown in Table 1. Admitting discipline differed between groups $(p=0.02)$, with more cardiovascular admissions in the ICU with wards. In the single-room ICU, there were more urgent admissions $(p=0.01)$ with higher co-morbidity $(p=0.03)$.

The mean $\kappa$ for agreement between the three observers $(\mathrm{O} 1, \mathrm{O} 2$ and $\mathrm{O} 3)$ on the mental status classification was $0.91(\kappa \mathrm{O} 1-2,0.91 ; \kappa \mathrm{O} 1-3,0.91 ; \kappa \mathrm{O} 2-3,0.91)$. When delirium occurred, the median number of days with delirium was 3 days (IQR 2-5) in the ICU with wards and 2 days (IQR $1-3)$ in the single-room ICU $(p=0.04)$. When we adjusted for confounding with Poisson regression analysis, the average number of days with delirium was 0.4 days $(95 \%$ CI $0.1-0.7)$ less in the single-room ICU than in the ICU with wards $(p=0.005)$, Table 2 . The risk of multicollinearity was considered low with no VIF or tolerance value meeting the thresholds. Overall, delirium occurred in $28(51 \%)$ patients in the ICU with wards versus $34(45 \%)$ patients in the single-room ICU [adjusted odds ratio (OR) 0.6, $95 \%$ confidence interval (CI) $0.3-1.6, p=0.53$ ], Table 2 . The severity of delirium, assessed with the mean daily DSI, was not different between the two environments, Table 2 . There was no difference in the proportion of patients that were physically restrained during any moment in their ICU admission nor in the number of days patients were physically restrained (data not shown). As shown in Table 3, we found no relationship between ICU environment and the use of propofol, benzodiazepines, opioids, clonidine or haloperidol. None of the included patients received quetiapine.

Table 1 Characteristics of study population

\begin{tabular}{|c|c|c|c|}
\hline & Old ICU $(n=55)$ & New ICU $(n=75)$ & $p$ value \\
\hline Age, mean (SD) & $59.9(15.5)$ & $58.2(18.3)$ & 0.57 \\
\hline Male gender, $n(\%)$ & $36(66 \%)$ & $44(59 \%)$ & 0.47 \\
\hline APACHE II, mean (SD) & $16.3(9.7)$ & $18.5(6.5)$ & 0.13 \\
\hline CCI, median (IQR) & $0(0-2)$ & $1(0-3)$ & 0.03 \\
\hline SOFA max, mean (SD) & $6.7(4.4)$ & $6.5(3.8)$ & 0.81 \\
\hline Admitting discipline, $n(\%)$ & & & 0.02 \\
\hline General medicine & $14(26 \%)$ & $22(29 \%)$ & \\
\hline General surgical & $4(7 \%)$ & $15(20 \%)$ & \\
\hline Cardiovascular ${ }^{\mathrm{a}}$ & $27(49 \%)$ & $18(24 \%)$ & \\
\hline Neurological $^{\mathrm{b}}$ & $10(18 \%)$ & $20(27 \%)$ & \\
\hline Admission type, $n(\%)$ & & & 0.01 \\
\hline Urgent & $33(60 \%)$ & $62(83 \%)$ & \\
\hline Elective & $22(40 \%)$ & $13(17 \%)$ & \\
\hline ICU LOS; days, median (IQR) & $5(2-10)$ & $4(3-8)$ & 0.56 \\
\hline Mechanical ventilation, $n(\%)$ & $52(95 \%)$ & $63(84 \%)$ & 0.06 \\
\hline Days of mechanical ventilation, median (IQR) & $2(1-8)$ & $2(1-5)$ & 0.24 \\
\hline Mortality, $n(\%)$ & $2(4 \%)$ & $7(9 \%)$ & 0.72 \\
\hline
\end{tabular}

APACHE acute physiology and chronic health evaluation, $C C I{ }^{\text {a }}$ Including cardiothoracic surgery

Charlson co-morbidity index, ICU intensive care unit, IQR inter- ${ }^{\mathrm{b}}$ Including neurosurgery

quartile range, $L O S$ length of stay, $S D$ standard deviation, $S O F A$

sequential organ failure assessment 
Table 2 Main outcomes and multivariate regression analysis

\begin{tabular}{|c|c|c|c|}
\hline Delirious patients $^{\mathrm{a}}$ & Old ICU $(n=28)$ & New ICU $(n=34)$ & $p$ value \\
\hline Crude number of days with delirium, median (IQR) & $3(2-5)$ & $2(1-3)$ & 0.04 \\
\hline Adjusted difference in the number of days with delirium, $(95 \% \mathrm{CI})^{\mathrm{b}}$ & Reference & $-0.4(-0.7$ to -0.1$)$ & 0.005 \\
\hline Mean DSI per day with delirium, mean (SD) & $2.3(0.7)$ & $2.5(0.8)$ & 0.34 \\
\hline Adjusted difference in DSI, $(95 \% \mathrm{CI})^{\mathrm{b}}$ & Reference & $0.3(-0.2$ to 0.7$)$ & 0.22 \\
\hline Days spent comatose, median (IQR) & $4(0-5)$ & $1(1-4)$ & 0.33 \\
\hline Mortality, $n(\%)$ & $1(4 \%)$ & $3(9 \%)$ & 0.72 \\
\hline All patients & Old ICU $(n=55)$ & New ICU $(n=75)$ & $p$ value \\
\hline Crude risk of delirium during ICU admission ${ }^{\mathrm{a}}, n(\%)$ & $28(51 \%)$ & $34(45 \%)$ & 0.53 \\
\hline Adjusted odds ratio for delirium, OR $(95 \% \mathrm{CI})^{\mathrm{a}, \mathrm{b}}$ & Reference & $0.6(0.3-1.6)$ & 0.53 \\
\hline Mean RASS, mean (SD) & $-1.1(1.1)$ & $-1.3(1.4)$ & 0.55 \\
\hline Days spent comatose, median (IQR) & $0(0-4)$ & $0(0-2)$ & 0.94 \\
\hline
\end{tabular}

$C I$ confidence interval, $D S I$ delirium severity index, $I C U$ intensive care unit, $I Q R$ interquartile range, $O R$ odds ratio, $R A S S$ Richmond agitation and sedation score, $S D$ standard deviation

a Assessed by review of medical and nursing charts and the confusion assessment method for use in the intensive care unit (CAM-ICU)

${ }^{\mathrm{b}}$ Models adjusted for age, gender, APACHE II, Charlson comorbidity index, highest SOFA score, admission type and admitting discipline

Table 3 Haloperidol, sedatives and analgesics use during ICU admission

\begin{tabular}{|c|c|c|c|}
\hline & Old ICU $(n=55)$ & New ICU $(n=75)$ & $p$ value \\
\hline \multicolumn{4}{|l|}{ Haloperidol } \\
\hline Number of patients using haloperidol, $n(\%)$ & $16(21 \%)$ & $20(27 \%)$ & 0.76 \\
\hline Average amount of haloperidol per patient, mg/day, median (IQR) & $4(2-6)$ & $3(2-5)$ & 0.24 \\
\hline \multicolumn{4}{|l|}{ Propofol } \\
\hline Number of patients using propofol, $n(\%)$ & $34(62 \%)$ & $41(55 \%)$ & 0.42 \\
\hline Average amount of propofol per patient, mg/day, median (IQR) & $1,304(664-2,910)$ & $1,360(588-2,923)$ & 0.92 \\
\hline \multicolumn{4}{|l|}{ Opioids } \\
\hline Number of patients using opioids, $n(\%)$ & $47(85 \%)$ & $59(79 \%)$ & 0.33 \\
\hline $\begin{array}{l}\text { Average amount of opioids per patient in fentanyl equivalents, } \\
\text { mg/day, median (IQR) }\end{array}$ & $0.13(0.06-0.28)$ & $0.16(0.05-0.38)$ & 0.39 \\
\hline \multicolumn{4}{|l|}{ Benzodiazepines } \\
\hline Number of patients using benzodiazepines, $n(\%)$ & $35(64 \%)$ & $43(47 \%)$ & 0.47 \\
\hline $\begin{array}{l}\text { Average amount of benzodiazepines per patient in diazepam } \\
\text { equivalents, mg/day, median (IQR) }\end{array}$ & $13(7-69)$ & $35(7-96)$ & 0.65 \\
\hline \multicolumn{4}{|l|}{ Clonidine } \\
\hline Number of patients using clonidine, $n(\%)$ & $12(22 \%)$ & $20(27 \%)$ & 0.53 \\
\hline Average amount of clonidine per patient, mg/day, median (IQR) & $262(82-508)$ & $259(145-437)$ & 0.79 \\
\hline
\end{tabular}

$I C U$ intensive care unit, $I Q R$ interquartile range, $m g$ milligram

On the days of our light measurements we found no difference $(p=0.70)$ in hours of sunshine with median (IQR) of $1.0(0.2-4.0) \mathrm{h}$ in the ward-like ICU and 2.5 $(0-5.2) \mathrm{h}$ in the single-room ICU. Also, there was no difference $(p=0.94)$ in the cloud cover between the ward-like ICU [median (IQR) cloudiness of 6.0 (5.5-8.0)] and the single-room ICU [6.0 (6.0-6.5)]. A total of 103,680 light intensity measurements were performed. Overall, median light intensity in the ICU with wards was $0.31 \mathrm{~V} / \mathrm{min}$ (IQR $0.24-0.38$ ) and in the singleroom ICU $0.52 \mathrm{~V} / \mathrm{min}$ (IQR 0.39-0.74, $p<0.001$ ). During the day, median light intensity was particularly lower in the ICU with wards $(0.42 \mathrm{~V} / \mathrm{min}$, IQR $0.35-0.55)$ than in the single-room ICU $(0.81 \mathrm{~V} / \mathrm{min}$, IQR $0.60-1.17, p<0.001$, Fig. 2). However, during the night, light intensity was similar with median (IQR) light intensity of $0.05 \mathrm{~V} / \mathrm{min}$ (IQR $0.04-0.10$ ) in the ICU with wards and $0.05 \mathrm{~V} / \mathrm{min}(0.03-0.09)$ in the single-room ICU, $p=0.52$.

\section{Discussion}

This study suggests that a change in ICU environment can decrease the number of days with delirium during ICU admission. In an ICU with all single rooms, we found that patients spent fewer days with delirium than in a conventional ICU with wards. Reducing the duration of delirium is of pivotal importance to ICU patients as each 


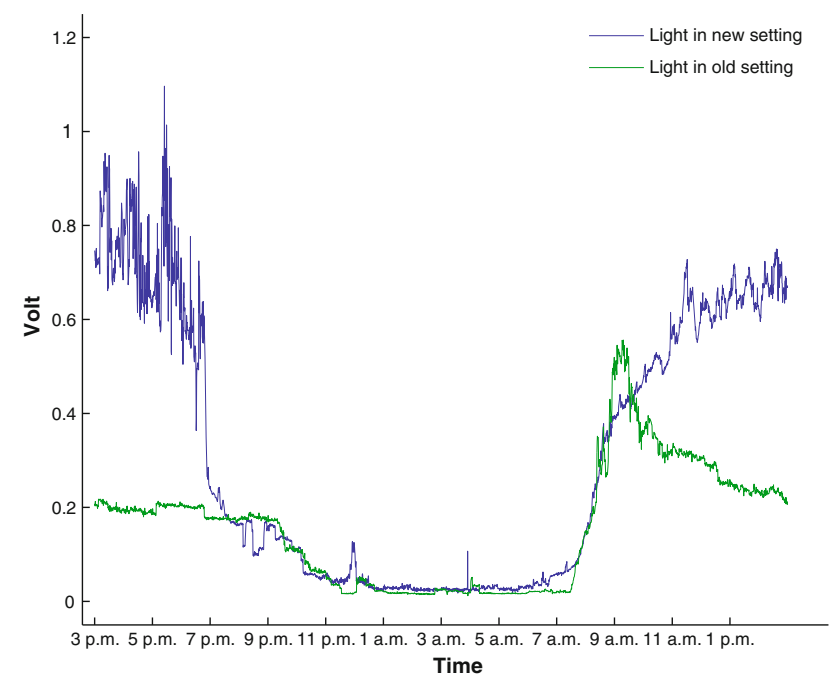

Fig. 2 Light intensities in the ICU with wards (old) and single rooms (new)

additional day with delirium in the ICU has been found to be associated with a $10 \%$ increased risk of death $[6,31]$.

Since the development of ICUs in the 1950s, the main focus of intensive care medicine was the survival of the patients, whereas less attention was paid to the environment in which this was established. However, the nursing environment, and especially excessive noise or light, appeared to influence several healthcare outcomes [16]. Post-surgical patients with a view onto a natural scene had a shorter hospital stay than patients with windows facing a brick wall [32]. Studies focusing on ICU environment and patient outcomes are, however, sparse [15, 33]. This is the first study comparing different ICU environments and delirium in intensive care patients.

The strengths of this study include the 7 days a week assessments by research physicians with high interobserver agreement, which ensured good quality of the evaluations. Delirium often has a fluctuating course. Using both CAM-ICU assessments and chart evaluations we tried to minimize the influence of fluctuation of the symptoms on our daily mental status classification. Because of the strict follow-up, there were no missing data. The study populations included a wide spectrum of diseases and conditions representing a typical mixed-type adult ICU, ensuring generalization of the results. Although the sample size of our study population $(n=130)$ was relatively small, the number of observation days was high $(n=917)$.

However, this study has some limitations. Most important is the before-after study design and the possibility that other factors than ICU environment have changed over time and influenced our findings. Between the two settings there were, however, no changes in doctor-patient or nurse-patient ratios, nor in practice or protocols for sedation, analgesia and delirium. We further adjusted for all differences in patient characteristics between the two ICU settings.

A source of bias may be that the two research physicians were aware of the change in ICU environment and the aim of the study. Theoretically, blinding would overcome this limitation, but this is impossible to apply in a study on the effects of ICU environment. Because of the high specificity of the CAM-ICU performed in daily practice by bedside nurses [25], who were not aware of the aim of the study, their CAM-ICU screening was taken into account in the daily mental status classification.

Up until now it was unclear how to quantify the severity of delirium; therefore, there was no golden standard for rating the severity of delirium. Without a golden standard it is not possible to validate severity instruments. In our study we made use of the DSI, which has also not been validated yet. The use of the Charlson co-morbidity index in studies regarding delirium is limited because it does not register relevant co-morbidity for delirium, such as cognitive decline, drug or alcohol abuse and other psychiatric disorders.

We have used a multicomponent intervention. However, our results could be subject to confounding by nonenvironmental factors or any other environmental change. The use of specific medication or physical restraints, undertreated pain and the duration of mechanical ventilation are possible risk factors for the development of delirium $[7,13,34,35]$. In our study population, the duration of mechanical ventilation and the use of psychoactive medication, opioids and physical restraints were not different between the two settings. Unfortunately, we did not register pain in our study. However, possible differences in pain may be related to the changes in the ICU environment, as shown in patients after cholecystectomy [32]. Differences in pain between the two settings may therefore be one of the intermediate factors in the causal relationship between the intensive care unit environment and delirium. In our study we have measured light intensities as one part of the multicomponent intervention. In the literature light levels are generally expressed in either volts or lux. Whereas lux is correlated to the light perceived by the human eye, a photodiode (measuring light in volts) is much more sensitive. Therefore, linear conversion from volts to lux is only possible within the visible spectrum. In both the ICU with wards and the single-room ICU, we measured light beyond the visible spectrum, hampering conversion to lux. Unfortunately, in our study we did not incorporate measurement of other environmental factors, such as noise levels.

Finally, we used Poisson regression to analyse differences in the number of days with delirium and did not include the time-varying nature of delirium. We cannot exclude potential immortal time bias, as the sickest patients are most likely to die early during critical illness with less opportunity to develop delirium [36]. However, in the two settings there was no difference in mortality, 
nor in the occurrence rate of delirium in the patients who died. Therefore, the risk of immortal time bias in our data was considered low.

\section{Conclusions}

This study is the first to assess the influence of ICU environment on delirium in the ICU. Our study suggests that environmental factors can influence the number of days with delirium during ICU admission, broadening the evidence for the effectiveness of non-pharmacological measures in the treatment of delirium. Future research should focus on single interventions in the ICU environment to determine the influence of ICU environmental factors on delirium. As the ICU environment appears to influence the course of delirium, non-pharmacological anti-delirium measures deserve more attention in intensive care medicine.

Acknowledgments The authors thank A.W. van der Kooi, MSc, Department of Intensive Care Medicine, University Medical Centre Utrecht, Utrecht, the Netherlands, for her assistance in analysing the data concerning light intensities in the ICU.

Conflicts of interest The authors declare that they have no competing interests.

\section{References}

1. Ely EW, Girard TD, Shintani AK, Jackson JC, Gordon SM, Thomason JW, Pun BT, Canonico AE, Light RW, Pandharipande P, Laskowitz DT (2007) Apolipoprotein E4 polymorphism as a genetic predisposition to delirium in critically ill patients. Crit Care Med 35:112-117

2. Bergeron N, Dubois MJ, Dumont M, Dial S, Skrobik Y (2001) Intensive care delirium screening checklist: evaluation of a new screening tool. Intensive Care Med 27:859-864

3. American Psychiatric Association (2000) Diagnostic and statistical manual of mental disorders, 4th edn. Revision, Washington DC, pp 135-147

4. Ely EW, Gautam S, Margolin R, Francis J, May L, Speroff T, Truman B, Dittus R, Bernard R, Inouye SK (2001) The impact of delirium in the intensive care unit on hospital length of stay. Intensive Care Med 27:1892-1900

5. Thomason JW, Shintani A, Peterson JF, Pun BT, Jackson JC, Ely EW (2005) Intensive care unit delirium is an independent predictor of longer hospital stay: a prospective analysis of 261 nonventilated patients. Crit Care 9:R375R381

6. Ely EW, Shintani A, Truman B, Speroff T, Gordon SM, Harrell FE Jr, Inouye SK, Bernard GR, Dittus RS (2004) Delirium as a predictor of mortality in mechanically ventilated patients in the intensive care unit. JAMA 291:1753-1762

7. Ouimet S, Kavanagh BP, Gottfried SB, Skrobik Y (2007) Incidence, risk factors and consequences of ICU delirium. Intensive Care Med 33:66-73
8. Lin SM, Liu CY, Wang $\mathrm{CH}$, Lin $\mathrm{HC}$, Huang CD, Huang PY, Fang YF, Shieh MH, Kuo HP (2004) The impact of delirium on the survival of mechanically ventilated patients. Crit Care Med 32:2254-2259

9. Marcantonio ER, Flacker JM, Wright RJ, Resnick NM (2001) Reducing delirium after hip fracture: a randomized trial. J Am Geriatr Soc 49:516-522

10. Inouye SK, Bogardus ST Jr, Charpentier PA, Leo-Summers L, Acampora D, Holford TR, Cooney LM Jr (1999) A multicomponent intervention to prevent delirium in hospitalized older patients. N Engl J Med 340:669-676

11. Lundstrom M, Edlund A, Karlsson S, Brannstrom B, Bucht G, Gustafson Y (2005) A multifactorial intervention program reduces the duration of delirium, length of hospitalization, and mortality in delirious patients. J Am Geriatr Soc 53:622-628

12. Hipp DM, Ely EW (2012) Pharmacological and nonpharmacological management of delirium in critically ill patients. Neurotherapeutics 9:158-175

13. Van Rompaey B, Elseviers MM, Schuurmans MJ, Shortridge-Baggett LM, Truijen S, Bossaert L (2009) Risk factors for delirium in intensive care patients: a prospective cohort study. Crit Care 13:R77

14. van Eijk MM, Slooter AJ (2010) Delirium in intensive care unit patients. Semin Cardiothorac Vasc Anesth 14:141-147
15. Van Rompaey B, Elseviers MM, Van Drom W, Fromont V, Jorens PG (2012) The effect of earplugs during the night on the onset of delirium and sleep perception: a randomized controlled trial in intensive care patients. Crit Care 16:R73

16. Ulrich RS, Zimring C, Barch XZ, Dubose J, Seo HB, Choi YS, Quan X, Joseph A (2008) A review of the research literature on evidence-based healthcare design. HERD 1:61-125

17. Ely EW, Truman B, Shintani A, Thomason JW, Wheeler AP, Gordon S, Francis J, Speroff T, Gautam S, Margolin R, Sessler CN, Dittus RS, Bernard GR (2003) Monitoring sedation status over time in ICU patients: reliability and validity of the Richmond agitation-sedation scale (RASS). JAMA 289:2983-2991

18. Teasdale G, Jennett B (1974) Assessment of coma and impaired consciousness. A practical scale. Lancet 2:81-84

19. Kesecioglu J, Schneider MME (2012) The intensive care unit of tomorrow: a case study of patient-centred care. ICU Management 12:12-13

20. Charlson ME, Pompei P, Ales KL, MacKenzie CR (1987) A new method of classifying prognostic comorbidity in longitudinal studies: development and validation. J Chronic Dis 40:373-383

21. Knaus WA, Draper EA, Wagner DP, Zimmerman JE (1985) APACHE II: a severity of disease classification system. Crit Care Med 13:818-829 
22. Vincent JL, de MA, Cantraine F, Moreno R, Takala J, Suter PM, Sprung CL, Colardyn F, Blecher S (1998) Use of the SOFA score to assess the incidence of organ dysfunction/failure in intensive care units: results of a multicenter, prospective study. Working group on "sepsis-related problems" of the European Society of Intensive Care Medicine. Crit Care Med 26:1793-1800

23. Ferreira FL, Bota DP, Bross A, Melot C, Vincent JL (2001) Serial evaluation of the SOFA score to predict outcome in critically ill patients. JAMA 286:1754-1758

24. Vreeswijk R, Toornvliet A, Honing MLH, Bakker K, De Man T, Daas G, Spronk PE, de Jonghe JF, Kalisvaart KJ (2009) Validation of the Dutch version of the confusion assessment method (CAM-ICU) for delirium screening in the intensive care unit. Neth J Crit Care 13:73-78

25. van Eijk MM, van den Boogaard $M$, van Marum RJ, Benner P, Eikelenboom $\mathrm{P}$, Honing ML, van der Hoven B, Horn J, Izaks GJ, Kalf A, Karakus A, Klijn IA, Kuiper MA, de Leeuw FE, De Man T, van der Mast RC, Osse RJ, de Rooij SE, Spronk PE, van der Voort PH, van Gool WA, Slooter AJ (2011) Routine use of the confusion assessment method for the intensive care unit: a multicenter study. Am J Respir Crit Care Med 184:340-344
26. Milbrandt EB, Deppen S, Harrison PL, Shintani AK, Speroff T, Stiles RA, Truman B, Bernard GR, Dittus RS, Ely EW (2004) Costs associated with delirium in mechanically ventilated patients. Crit Care Med 32:955-962

27. Zitman FG, Couvee JE (2001) Chronic benzodiazepine use in general practice patients with depression: an evaluation of controlled treatment and taper-off: report on behalf of the Dutch Chronic Benzodiazepine Working Group. Br J Psychiatry 178:317-324

28. Patanwala AE, Duby J, Waters D, Erstad BL (2007) Opioid conversions in acute care. Ann Pharmacother 41:255-266

29. Royal Netherlands Meteorological Institute (2012) KNMI weather database of weather station De Bilt. Available via KNMI. http://www.knmi.nl/datacentre. Accessed 28 June 2012

30. Groen G, Sluijter R, Stammes P, Ilderda $R$ (2012) Implementation of the Hinssen-Knap algorithm for the calculation of sunshine duration. KNMI publication TR-319. Available via KNMI. http://www.knmi.nl. Accessed 28 June 2012

31. Pisani MA, Kong SY, Kasl SV, Murphy TE, Araujo KL, Van Ness PH (2009) Days of delirium are associated with 1-year mortality in an older intensive care unit population. Am J Respir Crit Care Med 180:1092-1097
32. Ulrich RS (1984) View through a window may influence recovery from surgery. Science 224:420-421

33. Flaatten H (2005) Effects of a major structural change to the intensive care unit on the quality and outcome after intensive care. Qual Saf Health Care 14:270-272

34. Dubois MJ, Bergeron N, Dumont M, Dial S, Skrobik Y (2001) Delirium in an intensive care unit: a study of risk factors. Intensive Care Med 27:1297-1304

35. Morrison RS, Magaziner J, Gilbert M, Koval KJ, McLaughlin MA, Orosz G, Strauss E, Siu AL (2003) Relationship between pain and opioid analgesics on the development of delirium following hip fracture. J Gerontol A Biol Sci Med Sci 58:76-81

36. Shintani AK, Girard TD, Eden SK, Arbogast PG, Moons KG, Ely EW (2009) Immortal time bias in critical care research: application of timevarying Cox regression for observational cohort studies. Crit Care Med 37:2939-2945 